\title{
Considering the Relational Contours of Sociological Research Methods
}

Written by:

Patrick John Burnett

$\mathrm{PhD}$, Sociology

University of British Columbia

E-mail: patrick.burnett@outlook.com

Web: https://www.sociologix.ca

(C) Patrick John Burnett, 2014 


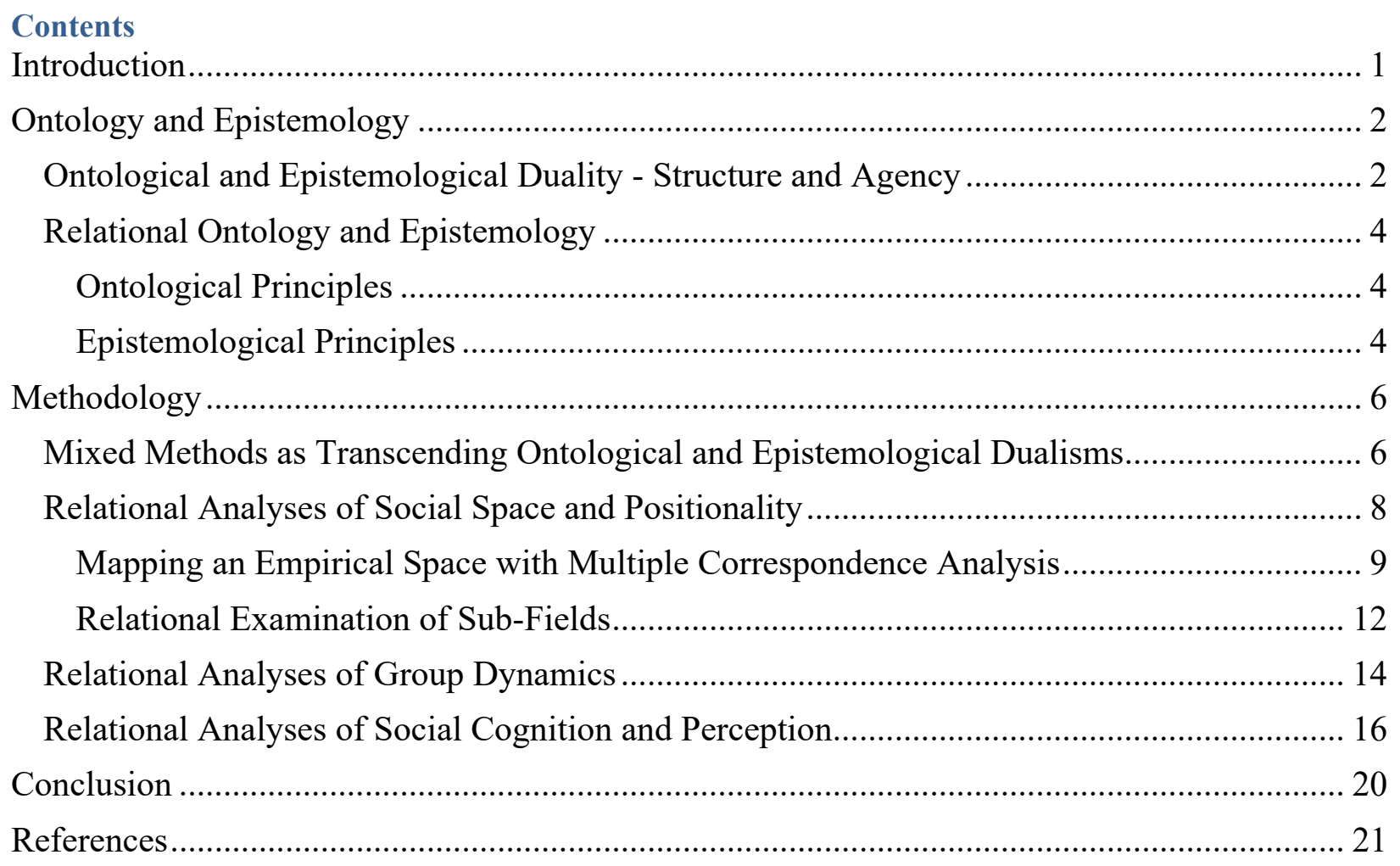




\section{Introduction}

Research methods are often seen as a standalone branch in any academic discipline. In the social sciences it is typically treated as the "practical" aspect of academic training that teaches you how to properly study society and social behaviour, to test your theories, explore and explain social phenomena through investigative models, draw conclusions, make assertions about social reality, and ultimately use the information to mark out empirical pathways to social change. In general, the term 'method' refers to procedures, techniques, processes, a systematic way to do something, a course of action taken to reach a research goal. Within the broader context of sociological research design, methods stand alongside ontology and epistemology as one of three equally important pillars supporting any research project. Broadly defined, ontology is a term that refers to the logic of existence, a conceptual mapping or theory concerning what-there-really-is in the world, and has to do with our assumptions about how the world is made up and what is the very nature and essence of things in the social world and of social reality. Finding a definition alongside ontology, epistemology is concerned with forms of knowledge or evidence of things in the social world and the operations of understanding and discovering knowledge about social reality, "it is literally your theory of knowledge, and should therefore concern the principles and rules by which you decide whether and how social phenomena can be known, and how knowledge can be demonstrated" (Mason, 2002: 16). Alongside ontology (way of framing predicates of existence, sociality, and being) and epistemology (the nature of evidence and knowledge), methodology speaks to the established practices, procedures and techniques used to investigate the forms of knowledge and evidence deemed valid for understanding and explaining social reality. When considering the intricacies of research design and methodological choices, making logical connections between ontology, epistemology, and methodology is fundamental to the task of developing logically consistent and robust research strategies, yet it remains a practice that is all too often left in the realm of the assumed or the taken-for-granted.

Specific to my own research, the focus of this exploration into sociological methods will be on the lesser known but increasingly influential research paradigm called relational sociology. While relational sociology has deep roots in sociological theory, it has only recently been gaining attention as a unique methodological approach (Mische, 2011). Given the relative infancy of relational methods, discussions related to the logical consistency between relational ontology, epistemology, and methodology are lacking. Considering the growing presence of relational theories within sociological literature, it is important to offer equal treatment to methodological considerations that pertain to relational principles. Thus, the aim of this paper is to identify several of the core ontological and epistemological positions at the heart of a relational research paradigm and critically discuss several of the main methodological approaches and their accompanying analytic techniques that are currently being applied by relationally oriented sociologists.

The following will start with a brief introduction to the fundamentals of ontology and epistemology, followed by a specific discussion of the ontological and epistemological principles of a relational research paradigm. The second section will introduce some general methodological considerations related to making a logical connection with ontology and epistemology, with particular consideration given to the relevance of mixed methodology for relational research. The final three sections will critically examine what I have identified as three broad yet complementary relational methodological approaches: 1- relational analyses of spatial patterns and positionality, 
2- relational analyses of group dynamics, and 3- relational analyses of social cognition and perception. I will conclude with a critical summary.

\section{Ontology and Epistemology}

The very notion of 'social reality' is incredibly complex. What does it mean to consider the nature of social reality and how can we study the logic of social existence? While these kinds of fundamental questions can seem far beyond the scope of sociological enquiry, they help focus our attention beyond a general familiarity with the ontological components of the social world (e.g. people, minds, collectivities, relations, things, time, materials, cultures, structures etc.) and towards a more focused understanding of whether and how they relate or connect in social life (Mason, 2000). There are of course many different ontological versions of the composition and processes of social reality, some may be logically competing rather than complementary while some have similar ways of conceptualizing social entities and may be amenable to one another. Whether or not it is possible or meaningful to distinguish between: subject and object; mind and body; rationality, emotion, thought and feeling; nature and nurture etc., has been the subject of long-running disputes among positivists, interpretivists, feminists, realists, substantialists, essentialists, postmodernists, and so on (Bourdieu and Wacquant, 1992; Latour, 2005; Martin, 2011; Mason, 2000). To be sure, there are no 'right' answers to the question of what-there-reallyis in the world, there are many ontological perspectives that suggest different versions of the essential or component properties of social reality/ies. As social researchers we do not need to take a matter-of-fact ontological position at the outset, but we do need to be actively engaged with ontological considerations throughout the research process.

Ontological positions play an important part in formulating our epistemological positions on what we decide might represent knowledge or evidence of the ontological entities we identify as central. According to Mason (2002), your epistemology is your theory of knowledge, that which concerns the principles and rules by which you decide whether and how social phenomena can be known, and how knowledge can be discovered and demonstrated. Different epistemologies have different things to say about ontological issues and about what the status of knowledge and the principles of evidence can be. Epistemological considerations should therefore direct you towards working out exactly what you would count as evidence or knowledge of social entities, with the goal being to draw logical connections with our ontological positions, "your epistemology helps you to generate knowledge and explanations about the ontological components of the social world [..] which you have identified as central" (Mason, 2002: 16).

\section{Ontological and Epistemological Duality - Structure and Agency}

At the most fundamental level social reality is thought to consist of people and the world around them, social beings and the social world. The structural end of the ontological spectrum is grounded in the fundamental belief that the social world consists of both an internal and an external reality. Early sociologists - most notably, Emile Durkheim - sought to demarcate sociology from the 'pre-social' psychological forms of explanation by way of developing a scientific approach to 
the study of the social forces that exist independently of individual consciousness (Martin, 2011). Marked by an ontological belief in an external social reality consisting of measurable social facts (or objective things) and coupled with an epistemological belief that our ability to explain social life requires an objective account of the regularities of social nature (i.e. social facts). Society is conceived as a universal space governed by empirically identifiable pre-existing social rules, norms and laws (Fligstein \& McAdam, 2012), as "that which has already been assembled and acts as a whole [..] what has been gathered, bundled, and packaged together" (Latour, 2005: 43). From the position that social beings live within a pre-formed society with common-to-all social norms carries the implication that the internal ideas and tendencies of individual actors are not developed by themselves, rather, they are formed as a result of the external social forces (e.g. customs, norms, social conventions) that are imposed upon them throughout the process of socialization and formal and informal social education (Fligstein \& McAdam, 2012; Martin, 2003, 2011). The assumption of 'natural', 'normal', and 'essential' social facts that exist external to human influence has been a major point of critique by theorists from a wide range of disciplines, all of whom fundamentally question the mechanistic illusion that our selves macroscopically obey the external laws of 'nature', or in other words, that the mechanistic laws of nature impress upon individuals a robotic sensibility that at all times coincides with the natural laws of society (Bourdieu, 1992; Bourdieu \& Wacquant, 1992; Lizardo \& Strand, 2010).

At the other end of the ontological spectrum the focus is placed more squarely on the individual, whereby social reality is thought to be the emergent result of acting and interacting social beings. The essence of the position being that people and their actions matter immensely, social order is not part of the nature of things or the laws of nature, but exists as the product of human activity (Fele, 2008; Lizardo \& Strand, 2010). In short, social beings are complex actors who experience, think, interact, relate, communicate, decide, create, perceive, interpret, and have a significant influence on the production, composition and maintenance of the social world. Social reality does not simply exist as an influential force or constraining cause on social actions, rather, "it is the outcome of actions undertaken by actors with some sense (presumably imperfect) of the expectations others have and the likely reactions attendant to confirmation or non-confirmation of various expectations" (Martin, 2011: 327). Epistemologically speaking, it follows that knowledge and evidence of social reality needs to be gathered at the level of the individual, to investigate the nature of the values, characteristics, emotions, dispositions, beliefs, and practices that inform the emergence and persistence of the social world, "to study the concrete practices of social actors [...] [and] the local organization of the actions by which the social world is constituted" (Fele, 2008: 300).

These ontological and epistemological distinctions represent the foundation of the most deep seeded debates in the social sciences, that is, whether social reality is the result of structural forces imposed on social actors or if social actors are the source of structural formation. In response to this dialectical view of social reality as composed of a multitude of singular entities, be they social, human, non-human, groups, or through the process of socialization, relational sociology has recently emerged as an alternative research paradigm. 


\section{Relational Ontology and Epistemology}

\section{Ontological Principles}

A growing segment of the sociological community who reject the notion that one can posit discrete, pre-given units such as the individual or society as starting points of sociological analysis, have been seeking out alternative approaches to think differently about social reality, not as consisting primarily in substances and static 'things', but instead, in dynamic, continuous, and processual terms (Martin, 2003; Somers, 1994; Emirbayer \& Johnson, 2008). Starting at the level of interactions, relational perspectives take relations - rather than structures, individuals, groups, attributes, or categories - as the fundamental unit of social analysis, and seek to better understand the cultural processes and relational contexts within which social actions unfold (Mische, 2011; Mohr, 2000). A relational perspective is grounded in a situational understanding of social reality whereby it is believed that concepts cannot be defined on their own as single ontological entities; rather, the meaning of one concept can be deciphered only in terms of its 'place' in relation to the other concepts and entities (Somers, 1994).

While a relational conception of social reality might seem a bit obscure at first, it basically represents a shift in focus from conceiving of the social world as composed of interacting properties and substances (e.g., people, places, spaces, groups, non-humans) to a position that examines the 'reality' of the entities as being made of social relations (Bourdieu \& Wacquant, 1992; Latour, 2005; Mische, 2011). Relationalism is essentially a way of thinking about the social world in terms of relations, which means accepting that all that is social, all that occurs in society, emerges in relation to other social factors located in a variety of social contexts. In a more practical sense, to think relationally means that to truly understand the structure of social life one needs to investigate and explain the often unseen relational context among social elements 'from the inside' to show the underlying order and functional links within social space that account for similarities and differences among individuals (Martin, 2003). The fundamentals of this position assert that "association in the sense of connection and combination is a 'law' of everything known to exist. Singular things act, but they act together. Nothing has been discovered which acts in entire isolation. The action of everything is along with the action of other things. The 'along with' is of such a kind that the behavior of each is modified by its connection with others" (Emirbayer \& Johnson, 2008: 5-6).

\section{Epistemological Principles}

Some of the most influential thoughts about relational epistemologies date back to the 1930's, where social psychologist/sociologist Kurt Lewin was among a small minority arguing against what he called the "classificatory epoch", a prevalent research orthodox that stressed similarities or dissimilarities, rather than interdependence (Lewin, 1939: 887). Calling for a new framework of "constructs" that "[does] not express "phenotypical" similarities, but so-called "dynamical" properties - properties defined as "types of reactions" or "types of influences," (Lewin, 1939: 884), he was one of the early adopters of a relational position which aimed to transition from 'phenotypical' to 'dynamic' constructs based on interdependence, a transition which he thought to be one of the most important prerequisites for any science wishing to answer questions of causation. Similarly speaking to a re-envisioning of causation in relational terms, Abbott (1990) remarks that it "means rethinking how we assign causal meaning to "variables." In the narrative 
view, the meaning of a particular value of a "variable" is not fixed by its relation to other values of this variable among the other cases, but rather fluctuates with its status as one among the several values of different variables that make up various particular events" (7).

Relational epistemology does not deny that structures or people exist as ontological elements, just that they are not independent sources of knowledge about social reality. Knowledge and evidence of social reality is to be found at the level of relations of power and position between ontological entities (Martin, 2011). Rather than focus on the set of attributes or essences that reflect a social structure or the intrinsic characteristics or attributes of an actor, we must think in terms of the 'in-between', 'differences', 'positionality', and 'valence' - defined as the force of attraction or repulsion between social entities (Martin, 2011: 246-247). Speaking to the importance of thinking in terms of relations and interdependencies, Abbott (1990) argues that "social life doesn't actually occur in main effects, but rather in events/interactions. Gender, the disembodied characteristic, in fact causes nothing to happen. Men and women cause things to happen" (7). Knowledge of the social world is captured in the differences and power relations, not the substances or essences that can be directly identified in distinctly causal terms. Instead, autonomous categories defined by their attributes are reconceived more accurately as dynamic shifting sets of relationships (Mische, 2011).

Relational epistemology is focused on discovering evidence of social forces and power, attraction and repulsion, similarities and differences, position and opposition, the spaces in between that draw and hold ontological entities such as "society", "actors", "things", together. Knowledge and evidence of social reality is subsequently the uncertain (and unpredictable) product of the individual's relationships, in communication with spaces, people, non-humans and other ontological entities. Methodologically speaking, it is no easy task to think in terms of relations rather than in terms of substance and function, this point was made very early on by Lewin (1939) who wrote "it is more difficult to describe a fact in terms of its effect on others and its being affected by others (its conditional-genetic properties) than in terms of its appearance (phenotypical properties)" (888), and emphasized in a similar way by Bourdieu and Wacquant over 50 years later (1992) where they state that "it is easier to think in terms of realities that can be "touched with the finger," in a sense, such as groups or individuals, than in terms of relations" (228). True as these statements may be, there have been great successes in the social sciences by relational thinkers applying methodological techniques and tools to investigate these complex ontological and epistemological principles. As I will outline in the following section, the methodological tools that have been used by relational sociologists have had to make a similar break with dualistic thinking in their analytical considerations where established quantitative or qualitative techniques have had to be adapted, merged, and mixed to fit within a relational framework. Following a brief introduction to the notion of mixing methodologies, I will critically engage with several of the most influential relational methodological approaches that have been used to date. 


\section{Methodology}

\section{Mixed Methods as Transcending Ontological and Epistemological Dualisms}

Generally speaking there is an assumed connection between ontological and epistemological orientation and appropriate methodological and data analysis techniques. If a research aim is to identify influential social mechanisms that are related to common behaviours in a society, quantitative analytic techniques are often used for their capacity to explore general patterns across large populations (Ivankova, Creswell \& Stick, 2006). Conversely, if the aim is to explore the social processes and dynamics of the actions of individuals within social settings, qualitative analytic techniques are often used for their capacity to dig deeper into the situational context and nuances of social phenomena (Ivankova, Creswell \& Stick, 2006). The methodological debates between objective vs. subjective, quantitative, vs. qualitative, generalizable vs. situational, quantity vs. quality, or "cold and prickly" vs. "warm and fuzzy" reflect fundamental differences that also contrast different elements of the research process, "including the choice of sample size, the logic of data analysis, and the general orientation towards knowledge" (Small, 2011: 61). Historically this may be true, however, more recently the notion of either/or has been replaced with a more unifying position of both/and (Martin, 2011:242), a position with a relational flavour that has become synonymous with mixed methodology.

As Small (2011) describes, mixed methodology emerged as a response to the heated debates in sociology between ethnographers and survey interviewers where it was argued that fieldwork and survey methods have complementary strengths and weaknesses that could be integrated in a way that could lead to a "new style of research in which the two methods ceased to be viewed as epistemologically incompatible and in which researchers no longer felt compelled to choose sides" (60). Somewhat idealistically, early proponents of mixed methods saw it as a way to side-step the idea that epistemological paradigms necessarily led to particular methodological techniques, giving rise to a "functional" approach which held the position that "epistemology and method are not synonymous [...] [and] mixed methods data analysis techniques should not be dictated by the underlying epistemological orientation. Rather, they should stem from the research purpose" (Onweuegbuzie \& Teedle, 2003: 352). While the idea of setting aside ontological and epistemological "baggage" for the benefit of being able to freely choose research methods that fit a research purpose sounds like a reasonable idea, the notion that epistemology and method should be treated as disassociated ideas is problematic. Ironically, while a mixed method position was built with the good intention of dissolve the divide between opposing methodological camps, it may have given rise to a new and far more problematic divide between epistemology and methodology.

While one can certainly agree with the notion that methodological decisions need to stem from the research purpose, we mustn't forget that the research purpose is itself the emergent result of ontological and epistemological decisions and considerations, whether we like to admit it or not. While earlier proponents of mixed methods found power and freedom in using techniques that best fit the kind of questions they wanted to answer (Small, 2011), modern applications of mixed methods emphasize the importance of developing a better understanding of the kinds of ontological and epistemological positions that cohere with a mixed methodological framework (de Nooy, 2003; Hollstein, 2009; Zerubavel, 2007). As Breiger (2000) emphasizes, "once it is recognized, however, that different 'logics' of methods exist, choosing between them requires, so to speak, 
stepping outside their scope and recognizing that one has become a practical actor, an actor capable of choosing appropriately as well as correctly" (111). Having a working understanding of the connection between ontological and epistemological principles does not have to limit selection of methods, it can facilitate the ability to read across methodological traditions and yield new insights and new tools.

In a digital age where social phenomena are equally tied up in 'real' and 'virtual' social spaces, Venturini and Latour (2010) emphasize the importance of maintaining an open mind about methodological choices, going as far as to argue that we must erase the micro/macro and qualitative/quantitative borders that were formed in an era of scarcity. Arguing that the social sciences are entering an age of abundance of new forms of relational data, they make an important assertion about the role of electronic forms of data:

"The interest of electronic media lies in the fact that every interaction that passes through them leaves traces that can be easily recorded, massively stored and inexpensively retrieved. Each day, researchers discover new pools of digital data: public and private archives are sucked into computer memory, economic transactions migrate online, and social networks take root on the web. Digital mediation spreads out like a giant roll of carbon paper, offering the social sciences more data than they ever dreamt of." (Venturini \& Latour, 2010: 6)

Thanks to digital traceability of virtual forms of data, they argue that researchers no longer need to choose between precision and scope in their observations, but can finally have the freedom to follow a multitude of interactions and processes of transition and change of social phenomena along the 'digital folds' of collective life (Venturini \& Latour, 2010). Similar sentiments are held by Bazeley, a promoter of complex computerized mixed methods data analysis, who finds that "mixed methods studies are being deliberately designed to employ and work with data in forms and ways that recognize the complexity of the human subject and the inadequacy of any one approach to developing knowledge and understanding of the human condition" (2003: 389). To be sure, the argument can and should be made that any and all instances of social enquiry can benefit from taking an eclectic approach to methodological choices, but the point I wish to make in the following sections is that relational ontological and epistemological principles fit particularly well - dare I say, are synonymous - with the idea of mixing methods. Being foundationally grounded in the notion that understanding social life requires exploring the often unseen relational context among social elements, at the level of relations, maximizing the variety of contexts and range of evidence is important to carrying out relational research.

Each of the following sections will walk through some of the established research methods that have been used as tools and techniques for generating the evidence that corresponds with the relational ontological and epistemological principles described thus far. Adding further context to the ontological and epistemological ideas discussed in the last sections, I will discuss 3 distinct ways in which relational ontology and epistemology have been conceptualized methodologically: relational analyses of spatial patterns and positionality, relational analyses of group dynamics, and relational analyses of social cognition and perception. My discussion will be schematic rather than exhaustive, sketching some of the main analytic tendencies of relationally informed lines of investigation. 


\section{Relational Analyses of Social Space and Positionality}

Perhaps one of the most well known pathways to implementing a relational framework stems from field theory, which is simply described as a "more or less coherent approach whose essence is the explanation of regularities in individual action by recourse to position vis-a-vis others" (Martin, 2003: 1). Taking relations as the fundamental unit of analysis, field theory examines social phenomena as the result of the interdependent nature of human actions and complex social relations within the constraints of a social environment (Martin, 2011). Proponents of field theories share a common vision of social reality as consisting of distinct social spaces (fields) that have their own emergent regulative principles and internal logics (Bourdieu \& Wacquant, 1992). Each 'field' is believed to represent a social arena in which social elements interact and events take place, revealing the orientation of social life within social spaces. Analytically, fields are conceived as 'snapshots' of social reality, differently structured and representing distinct worlds with specific features that influence what is possible for actors located in them (Bourdieu \& Wacquant, 1992).

In relational terms, the ultimate goal when undertaking an analysis of fields is to construct an 'analogical model' of a field, a theoretical representation of a social space, that allows the researcher to explore how social factors in the form of objective properties are distributed among groups of individuals in social space (Bourdieu \& Wacquant, 1992). In order to unite theory and method in such a way, the researcher must use analytic 'tools' to depict a social space, distinguish zones of necessity and freedom, and expose an overall picture of the forces that speak to the principles of action and interaction that best represent a relational field (Breiger, 2000: 107). This kind of approach differs with current methods of analysis which are almost "uniformly based on such epistemological assumptions and consequently form an inventory of ways of linking variation in one attribute of some unit to variation in another of its attributes" (Martin, 2011: 273). Field methods, seek to "explain changes in the states of some elements without appealing to changes in states of other elements ("causes"), instead, explanation makes reference to a characteristic of the position of the element" (Martin, 2011:274).

One of the earliest applications of field analyses was in the 1930's by social psychologist/sociologist Kurt Lewin, whose relational investigations of dynamic equivalence between social environments, experience, and cognitive structures laid the foundation for generations of spatially oriented social research. Analytically, Lewin developed detailed empirical maps of what he called psychological environments, which were spatial depictions of the interdependent connections between cognition and environment that spoke to the potential for action being dynamically related to the position held by an actor within a social setting (Lewin, 1939: 878). His unique position on exploring the dynamics of interdependence and positionality within social fields emphasized the notion that what holds people together is just as important as understanding the characteristics of who they are. He offers several methodological points that are particularly related to the ontological and epistemological foundations of relational sociology and remain analytically relevant today:

1- the "meaning" of a single fact depends upon its position in the field, 2- the properties of a field as a whole, such as its degree of differentiation, its fluidity, and its atmosphere, should be emphasized sufficiently, and 3- one of the foremost tasks of fact-finding and observation in social psychology [and sociology] is to supply reliable data about properties of the field as a whole (Lewin, 1939: 891-94). 
Stepping outside of Lewin's focus on understanding the cognitive embodiment of a social space, these methodological principles speak more broadly about the importance of understanding the relational composition of social mechanisms and properties at play within social environments. Speaking specifically towards sociology's capacity to examine the social dimensions of an empirical space, he found the discipline particularly capable of "dealing with a multitude of coexistent interdependent facts- in other words, with the "empirical space"" (1939: 891) and urged sociologists to break from the popular prejudice of the time - accepting that physical space is the only empirical space - and to be confident in affording a social field the same "reality" as a physical one (891-92).

The work of Pierre Bourdieu is perhaps the most well-known instance of an empirical application of field theoretic principles that sought to understand the interdependent dynamics of social forces in an empirical space. Standing on familiar ground with Lewin, Bourdieu believed that "to construct an object is to construct a model, but not a formal model destined merely to turn in the void, rather a model intended to be matched against reality" (1992: 45). He sought to create a "relational philosophy of science devoted to the objective relations 'which one cannot show, but which must be captured, constructed and validated through scientific work', and a dispositional philosophy of action which notes the relations between 'the potentialities inscribed in the body of agents and in the structure of the situations where they act"' (Savage \& Silva, 2013:113-114).

\section{Mapping an Empirical Space with Multiple Correspondence Analysis}

Bourdieu's application of field analysis pays particular attention to the social, cultural, and symbolic mechanisms and properties that inform the dispositions that distinguish 'similar' and 'different' agents in social fields. For him, field analysis offers an analytic foundation for the structural mapping of socially oriented arenas of struggle and freedom, power and privilege, and is a key spatial metaphor used to illustrate the principles of differentiation embedded in a social setting in which resources, institutions and organizations interact and the habitus (i.e., psychological environment) operates (Bourdieu and Wacquant, 1992). His method for developing evidence of field dynamics is to construct 'analogical models' of fields, a theoretical representation of social spaces that facilitate the exploration of how social factors in the form of objective properties (variables) are distributed and connected to one another.

To implement his relational theory of fields, Bourdieu used spatial mapping technique called multiple correspondence analysis (MCA) to explore the relational composition of social mechanisms and properties that distinguish 'similar' and 'different' agents in a social space. The structural mapping was used to illustrate the principles of differentiation embedded in a social setting in which resources, institutions and organizations interact (objective positions) and individual level dispositions and values relate (subjective dispositions). It is "a technique which thinks in terms of relations" (Bourdieu \& Wacquant, 1992: 97), a way to expose the underlying patterns in survey data that express the categorical differences and similarities between people (correspondence) through a visual mapping of a 'social space'. MCA is an exploratory analytic technique used to examine the associations between multiple categorical variables by transforming the many associations present within a large matrix of cross-tabulations into a graphical representation/map of the variable categories as scattered points in a computer-generated in a 
multi-dimensional social space (de Nooy, 2003). This technique allows researchers to inductively discover the structure inherent in the data (Rouanet et al., 2000) and permits the transformation of a table of numerical information into a graphical display that facilitates the interpretation and exploration of the data (Greenacre, 1994).

MCA is a geometric mapping technique rather than a statistical one, where the only statistical concept to which MCA is linked is the Pearson chi-square statistic, "which is regularly computed for cross-tabulations in order to assess the significance of the associations between row and column variables" (Greenacre, 1994: 8). The geospatial maps cluster categories that co-occur relatively often and helps to understand the content of the associations among the variables in a clean visual form (de Nooy, 2003: 307). As an exploratory technique, MCA does not 'think' in terms of causal relationships nor does it follow the theoretical assumptions of more conventional linear modeling techniques like regression analyses. While this remains one of the strongest criticisms against MCA - the absence of hypothesis testing and thus the charge that it is 'theoryless' - Greenacre (1994) agrees that there should be theory and emphasizes that it include "assumptions on how the variables to be analyzed are connected to one another" (23). This thoroughly relational statement stresses the importance of following a set of theoretical and empirical rules necessary to set up an exploratory social space that is robust and operates as a 'snapshot' of social reality.

First, the construction of a model of social space must start with a theoretical, empirical and intuitive understanding of the social factors that are believed to be the most relevant representations of positions within social space (Bourdieu \& Wacquant, 1992: 233). Specific to MCA analysis one has to make the important choice of which social factors (i.e., variables) will be included as structuring or supplementary factors, also known as active or passive variables (see Greenacre, 1994, for detailed description of this process). Second, examine the dimensions of the social space. Once the variables have been chosen and positioned as either active or passive factors, the data is reduced into a number of dimensions that each explain different proportions (percentage) of the variance in the data. The variance explained in each dimension is represented by a series of eigenvalues which essentially provide a numerical representation of the percentage of explained variance (or inertia) of each dimension in the model (Greenacre, 1994; de Nooy, 2003). They are, in Bourdieu's application of correspondence analysis, a way to index the dimensions of social fields and means to "visualize proximities between specific response levels of a questionnaire and characteristics of the respondents, demonstrating the association between certain types of cultural profiles and certain social situations" (Breiger, 2000: 111).

Generally speaking, the higher the inertia, the more spread out and dispersed (distinct and different) are the categories in space, meaning that there is more variance among respondents and the profiles in the multidimensional space will be more distinct. The choice of number of dimensions to include in an analysis should make empirical (i.e., eigenvalues and scree plot) and substantive sense (i.e., make theoretical sense and be meaningfully different). Third, exploring and interpreting the social space (i.e., correspondence map) comprises two fundamental stages: 1) interpreting each of the dimensions (axes) by looking at important questions and important categories (interpreting the eigenvalues and factor contributions, and 2) visually inspecting the positions of categories in the graphical map and where they lie relative to one another (Greenacre, 1994; Rouanet et al., 2000). 
The technical specifications of MCA - the preferred method of relational analysis for Bourdieu - paints a picture of a highly objective analytic technique that operates on the identification of common properties and characteristics of individuals, which could be argued is antithetical to the relational ontological and epistemological principles described earlier (Rouanet et al., 2000). While this is true in the sense that the method begins with the identification of 'properties' or 'characteristics' of respondents, the method is fundamentally aimed at understanding the relations between properties (bundles of relations), wherein "the fact that one property usually entails another and excludes a third is deemed socially meaningful" (de Nooy, 2003: 309). A focus on the 'forces' that draw certain social properties together in a social space is a required frame of thinking when disseminating the results of an MCA, this is however, not as simple a task as it would seem, as is captured by Bourdieu's warning that "you must beware at every moment of regression to the "reality" of preconstructed social units" (Bourdieu \& Wacquant, 1992: 230). This refers to the constant urge to explain clusters of people in a model based solely on their common categories and properties.

For Bourdieu, MCA was a way to "link pertinent data in such a manner that they function as a self-propelling program of research capable of generating systematic questions liable to be given systematic answers, in short, to yield a coherent system of relations which can be put to the test as such" (Bourdieu \& Wacquant, 1992: 233). The analogical reasoning he applies in disseminating the models is "based on the reasoned intuition of homologies" (Bourdieu \& Wacquant, 1992: 233), which he describes as "resemblance in difference", a mode of thinking comparatively about positionality within fields (i.e., the fit between objective structures and subjective structures in a field) but also "the structural homologies that exist between different fields" (Bourdieu \& Wacquant, 1992: 234). The term homology is important to think relationally about the structure of fields, as a way to think about what forces connect different levels of beliefs, practices, properties, resources, and capitals within fields but also how underlying relations (i.e. struggles) and cultural distinctions within fields have homologous effects in other fields (de Nooy, 2003).

Bourdieu himself recognized some of the limitations of relational analyses and the tendency to emphasize the force and prominence of properties in relational models, stating that "one of the main difficulties of relational analysis is that, most of the time, social spaces can be grasped only in the form of distributions of properties among individuals or concrete institutions, since the data available are attached to individuals or institutions" (Bourdieu \& Wacquant, 1992: 230). To counteract this analytical limitation, he emphasizes the use of comparative methods to understand the dynamics of the sub-fields of the relational models, offering the example: "to grasp the subfield of economic power in France, and the social and economic conditions of its reproduction, you have little choice but to interview the top two hundred French CEOs" (Bourdieu \& Wacquant, 1992: 230). In a very similar way Zerubavel (2007) argues that comparative methods are "one of the principal methods of sociological enquiry that entails drawing on multi-contextual evidence. Ultimately searching for general patterns that transcend any one particular context" (134). Emphasizing the importance of thinking beyond methodological dualities, both are saying that in order to explore within context (i.e. sub-fields) and across context dynamics (i.e., across sub-fields) we need to draw upon multi-contextual evidence and research techniques. While Bourdieu often shies away from in depth discussions of the qualitative dimensions of his analyses in Distinction, he does confess in the methodological appendix that "in view of the limits of the [survey] data collected and of any information obtained in such an artificial situation as 
interrogation by questionnaire, recourse was had throughout the analysis - whenever a difficulty arose or a new hypothesis required it - to observations and questionings [interviews] in real situations" (Bourdieu, 1984: 508-509). Reflecting upon the illustrative role of MCA as a way to describe data and get ideas about the structure of variables, he clearly states that "the 'concrete' analyses [MCA] are there to assist the return into the experience of the product of scientific description [..] The same is true of all the documents (facsimiles of books or articles, photographs, extracts from interviews etc.) which have been inserted in the text, in order to discourage absentminded readings which are abstract in the sense that they have no referent in reality" (Bourdieu, 1984: 510). While his use of multi-contextual evidence is rarely mentioned or acknowledged, it is a critical dimension of relational methodology that recognizes the importance of drawing upon different levels of evidence to contextualize the contours of the clusters and relations in an analogical model. Some of the strongest applications of Bourdieu's relational framework apply similar principles of multi-contextual evidence.

Dubois et al. (2013) present a particularly interesting example of research that successfully integrates MCA with ethnographic fieldwork to examine the relational dynamics of positionality within sub-fields. Specifically, their analysis of the relational form of sub-fields within broader musical fields in regions of France sought to explore the hierarchy of positions within sub-fields and show that even in dominated spaces, there exist levels of domination among the dominated (or levels of domination among the dominant). Strictly speaking on a methodological level, their study of wind music bands - a form of music that holds a dominated position within the broader musical field - used MCA to identify the spatial differences within this sub-population of musicians, to identify the relational characteristics of the musicians who could be classified as the 'dominated among the dominated' (Dubois et al., 2013: 138). Using ethnographic observations allowed the researchers to contextualize the results of the MCA with concrete experiences and direct interactions. They conclude by noting that "field analysis and the objectification of social spaces remain the most powerful, as they allow the results of an interpretive or interactionist approach to be placed in a more general perspective" (Dubois et al., 2013: 142).

The substantive importance of including contextual data to better understand the differences and similarities revealed in an objective analysis of fields introduces important methodological considerations pertaining to the investigation of sub-spaces or sub-fields. Aptly put by DiMaggio (1986), "structural measures of relations in fields have a wide range of applications. For some purposes, however, partitioning a population of organizations into, subpopulations and examining the relations among the subpopulations is essential" (340). Stemming from a common critique that Bourdieu was expert at explicating the relational dynamics within different fields but left much to be desired in his discussions about the dynamic relations between fields (e.g. how the academic field interplays with the religious field), pockets of sociological research guided by relational principles sought to examine more closely the inter- and intra-organization of fields and sub-fields and the sets of actors that occupy them.

\section{Relational Examination of Sub-Fields}

Partly influenced by the relational work of Bourdieu, Paul DiMaggio was one of the first to study dynamics of interacting sets of organizations (i.e., networks, populations, sectors, or domains). 
Relational at its core, this approach changes the level of analysis from the dynamic relations between objective and subjective elements within fields to the dynamic relations between organizational fields within broader fields, with the focus being on "the behaviour of sets of organizations, rather than of single organizations, and about relations among sets of organizations rather than between variables" (DiMaggio, 1986: 342). Particularly in line with the relational principles of Lewin and Bourdieu, when discussing strategies for mapping the structure of organizational fields, DiMaggio emphasizes that they should be based on "patterns of ties among organizations, rather than upon similarities in their social definition (naturalistic approach) or characteristics (attribute approach)" (1986: 345).

Thinking in terms of organizational partitions and sub-groups, DiMaggio applies blockmodeling analytic techniques to define role structures within groups, collectives, and networks. He defines blockmodeling as a sophisticated social network data reduction process that permits the analyst to "group members of a population into self-consistent subsets or "blocks" on the basis of the relations among them. Actors allocated to the same block are those with similar relationships to the same other actors (and not necessarily those who interact with one another, as in clique-detection approaches)" (DiMaggio, 1986: 346-347). Blockmodeling places actors in the same clusters not on the basis of a tie between them, but if they share a similar profile of ties to other actors in the network, "if they are in what is called a position of 'structural equivalence"' (Edwards, 2010: 11). Using network data on organizational representatives' network ties and social relations, DiMaggio applied blockmodeling techniques to arrange members of a population into groups of actors who were structurally equivalent on the basis of their received ties from other actors in the system. Presenting data on relations among blocks, each of which were considered as collectively occupying different structural positions in the field, a series of density matrices illustrate the patterns of domination, coalition, and no contact (i.e., inter-field relations) within groups (see DiMaggio, 1986: 351-353, for explicit details on pattern interpretation). To contextualize the nature of the relations between blocks, the final stage is describing the attributes of the occupants of the blocks.

Specific to relational thought, this method of analysis allows interpersonal relations to be the prime indicator of the position of persons in a field, but more importantly, an indicator of the position of fields (collectives of actively related actors) in relation to other fields. Where MCA identifies fields based on clusters of similar properties and dispositions among a population of respondents, blockmodeling provides a different understanding of fields as structurally based on the similar patterns of ties and orientation of actors to one another. Furthermore, it speaks to the complexity of the inter- and intra-field relations and the ways in which distinct fields may or may not change over time simply because there is more or less communication among the members from different fields. The appeal of using network methods of this sort for relational research is that it actively acknowledges that a field's structure is not merely reflected in objective relations, but also in the interactions or intersubjective relations that mediate and transform the forces of objective relations (de Nooy, 2003: 322). While blockmodeling remains focused at the level of field relations, other avenues in network methods further investigate the idea of cognitive mapping in networks, investigating the relational dynamics of what goes on within fields, communities, or networks. 


\section{Relational Analyses of Group Dynamics}

Examining more closely the cognitive contours of group dynamics among people within social spaces, social network analysis has developed as an approach for studying 'social relations' rather than 'individual attributes', as another kind of 'descriptive' method which can be used to unravel complex cultural patterns (Edwards, 2010; Savage \& Silva, 2013). Where Bourdieu and DiMaggio were examining social relations at the level of fields or organizations, network methods seek to better understand what relational dynamics are taking place at the level of interacting individuals and groups. While network methods often get labeled as structurally oriented techniques for mapping network structures and their patterned characteristics, they are also deeply relational when aimed at understanding cognitive functions in terms of positionality within groups rather than based solely on individual attributes (1988). In her examination of the relational basis of attitudes, Bonnie Ericson argued that units of analysis for attitudes should not be focused on isolated individuals but on social networks, and viable subjects for explaining social action are not individual attitudes but "degrees of attitude agreement among individuals in given structural situations" (1988: 99). From a relational position, she argue that attitudes are made, maintained or modified through interpersonal processes, which occur mainly within the boundaries of social networks.

In stark contrast to the position that similar people with similar characteristics share similar attitudes and share similar positions in social space, Ericson (1988) examines the processual dimensions of network dynamics such as frequency of interactions between people (dyads or triads) resulting in attitude adjustment and formation in relation to network actors; multiplexity, related to interpersonal connections and similarity in attitudes among network members; strength, where stronger and developed relationships lead to agreement and similar attitudes; and asymmetry, where a relationship in a network is more or less reciprocal can lead to more or less symmetrical attitudes (e.g. one actor feeling more connected to one actor in the network than to another). Examination of these dimensions allows for the identification of the constraining and enabling forces and processes of patterned relationships among social actors within intersecting and overlapping networks of social ties (Breiger, 2000; Emirbayer and Goodwin, 1994; Mische, 2011). The dimensions in question extend to the complex social, cultural, symbolic, and objective formations that enable or constrain the relational constellation and arrangements of resource exchange and transmission, knowledge translation and communication, and the distribution of power among diverse individuals, groups, and communities. In this way, relational sociology generally, and network analyses in particular, must consider relationships in their real and ideal forms, even if the tools for fully understanding the dynamics of their interplay have not been clearly specified (Silver \& Lee, 2012; Martin, 2011). Silver and Lee (2012) develop this point further by arguing that even the most basic network measure, degree centrality - determined by the number of people to whom one is related - has a self-relational dimension that is largely unexplored by network researchers. Specifically, they argue that degree centrality indicates that one likely participates in a broad array of social contexts (i.e., fields) via their relations with different persons and groups, and can be an important indicator of the scope of commitments and obligations one might have in multiple social spaces, that is, may be indicative of the social demands placed on individuals (Silver \& Lee, 2012: 222).

This line of thinking has deep ties with Simmel's theory of individualism and multiple group affiliations where "the specific qualities of the individual are preserved through the 
combination of groups which can be a different combination in each case" (1955: 163). For Simmel, "there is an analogous relationship between the individual and the groups with which he is affiliated [..] As the person becomes affiliated with a social group, he surrenders himself to it" (1955: 140-141). When considering the notion of multiple group affiliations, he argues that the genesis of the personality needs to be interpreted as the point of intersection of innumerable social influences (141). Simmel's argument that "the external and internal conflicts arise through the multiplicity of group-affiliations, which threaten the individual with psychological tensions [or] it can strengthen the individual and reinforce the integration of his personality" (1955: 142), is taken up by Silver and Lee in a contemporary methodological context when they assert that "a network position that situates one as a go-between for a diverse array of social contacts has an important analog for the person's life; one's commitments and identity may be larger or smaller" (2012: 222).

The importance of understanding the self-relational dimension of network affiliation has given rise to a branch of social network research arguing that the incorporation of qualitative data can help understand how actors in a network understand their relation to others within the multiple networks they belong to (Blazeley, 2003; de Nooy, 2003; Edwards, 2010; Hollstein, 2009). Edwards (2010) specifies that social network analysis has a dual interest in both the structure and form of social relations, whereby the interactional processes that generate the structures "have to be understood by exploring the 'content' and perception of the network (i.e. the 'insider' view of the network" (Edwards, 2010: 4). This dual interest in structure and form makes social network analyses well suited for the inclusion of qualitative approaches that can generate a range of narrative, observational and visual data on social networks that can help understand "how social networks are experienced and how they are embedded in spatial and temporal contexts" (Edwards, 2010: 7).

Qualitative methods of analysis such as content or thematic analysis can be used to unravel complex cultural patterns and infuse a processual dynamic that would be well situated among wider contextual findings (Savage \& Silva, 2013). Hollstein (2009) specifically mentions network analysis to be accompanied with qualitative methods such as participant observation; 'walking interviews' (where the participants were interviewed whilst leading the interviewer on a walk around their environment); diaries of communicative processes; and participatory visual mapping techniques. While the inclusion of qualitative data and analytic techniques along with a method that has been largely focused on understanding the dynamics of network structures and formation is central to a more complete understanding of the processes and form of a network, a relational approach requires that investigations of networks not be limited to a 'dual interest' model. Where the formal representations that are gained from network analytic techniques provide useful insight into complex patterning of relationships, and thus the structural opportunities, constraints, and dilemmas actors confront, Mische (2011) argues that the "representations need to be complemented by historical, ethnographic and interview research that examines the communicative interplay, strategic maneuvering, and reflective problem solving carried out by actors in response to the relational tensions" (17). Emphasizing the need to develop a deeper understanding of the cognitive dimensions of social relations, the final section will examine a relatively underdeveloped relational approach that build on recent theories of 'situated actions' in multi-layered social contexts and focuses on understanding the dynamic interplay between cognition, groups, settings, networks and culture. 


\section{Relational Analyses of Social Cognition and Perception}

Up to this point our methodological discussions have examined ways to develop knowledge about the position of an actor within social settings and how their relation to social forces in their environment and the form of connections and relations with actors shape their identity. All spatially oriented relational accounts, however, "require that our key elements be discoverable in first-person experience" (Martin, 2011: 283). While there are comparatively few examples of sociological research empirically examining the social dimensions of cognitive function and social action - though there are many theories on the topic - contemporary relational thinkers like John Levi Martin, Omar Lizardo, Ann Mische, Alford Young, and Margaret Somers, to name a few, are investigating the ways in which socially formed cognition - e.g. Lewin's psychological environment and Bourdieu's habitus - relate to actors' sense perceptions, aspirations, and understanding of the 'future'. Fundamental to this re-emergence of social cognitive framework is the notion that we have developed extensive knowledge of the ways in which past experiences and present situations inform the development of a social being (i.e., social cognition), but have yet to empirically explore the ways in which social forces are projected into future perceptions of possible or potential actions (Mische, 2009). Given that there are few empirical examples within the sociological literature, the following will be a brief discussion of some prospective methodological considerations that could be made when thinking relationally about the cognitive contours of social action.

There are many relational theories of practice that explore the ways in which social dimensions and relationships of everyday life are embedded into the psyche of social actors. Lizardo and Strand (2010) provide a detailed summary of the recent works attempting to formulate the relationship between culture and cognition. They take the position that practice theories and theorists are generally reluctant to venture into the cognitive side of the problem of explaining social action, often failing to ask the difficult questions about how cultural acquisition actually translates into cognitive functions and the practical decisions that people make in their day to day lives. Making particular mention of Bourdieu's theory of practice and contemporary adaptations/interpretations of his theory (citing the toolkit theory of Swidler and Breiger), they argue that "while offloading a lot of the cognitive activity of the actor to external structures and institutions" (Lizardo \& Strand, 2010: 212), it does not mean that implicit schemes of perception, appreciation and action do not matter. Quite the opposite, they, along with Ann Mische (2009) and John Levi Martin (2011), draw attention to the relational principles of Bourdieusian and Bourdieuinspired practice theory and argue that concepts such as habitus - defined broadly as the embodied skills and practical competences developed over time within social fields - when considered as 'ontologically complicit' with field, provide important inroads to think about practical consciousness and cognitive function of actors' practical mastery of a fields regularities and their ability to anticipate and understand the future. These principles speak to the fundamentally relational nature of interdependent actors whose view of the social world, their position in it, and perceptions of how to act, arise through their social experiences with the people, relationships, objects, rules, and forces within social spaces. Thus, in the context of being socialized to the processes and patterns within social spaces, people learn to adjust their actions to fit with the tendencies of the fields and shape their expectations and aspirations according to concrete and symbolic indices of the accessible and the inaccessible, of what is and is not 'for them' (Bourdieu and Wacquant, 1992; Bourdieu, 2000). 
Speaking about the connection between experience and perception, Martin (2011) notes "physical neural traces or remnants of past experience guided such perception and future neural activity" (260), a point that exemplifies the cognitive dimensions of Bourdieu's work, where he argues that the ability to anticipate the 'forth-coming' of events is an anticipatory ability that arises "from experience of the regularities of existence, structure the contingencies of life in terms of previous experience and make it possible to anticipate in practice the probable futures" (Bourdieu, 2000: 211). Thinking about the cognitive dimensions of socialization and experience within social spaces encourages us to think about how internalized social boundaries can also shape actors' relation to people, places, and groups that they interact with, and their ability to anticipate and comprehend how to act (Lizardo \& Strand, 2010). But what does this all mean methodologically?

Ann Mische, a strong voice among proponents of relational methodologies has called for more fruitful incorporation of 'the future' into sociological research and to revive the notion of projects, or projectivity, as a tool for social analysis (2009: 695). Her position is that analyses of future possibilities and projection must not be strictly based on the "objective" structural forces of fields on the actions of people, rather, she argues that "we should refocus attention on the open, indeterminate, "polythetic" perception of the field from the point of view of the actor surveying the future in terms of multiple possibilities" (Mische, 2009: 696). A relational vision of examining projection in fields can include investigations of projective dialogue, not simply dialogue with the individual actors' vision of their future self but also with other people who inhabit their social space and their imagined future. While the ideas summarized by Mische are grounded in a long history of social theory emphasizing the importance of considering the link between future projections and actions, there remains very little discussion of ways to connect the complex metaphysical discussion about future perception with methodological discussion about how to collect evidence of such principles.

Looking to extend the methodological considerations beyond phenomenology - research that "explores the intentional relationship between persons and situations, and discloses the essences, or structures, of meaning in human experiences" (Finlay, 2009: 18) - Mische offers a list of several cognitive dimensions of future projections that bear mention and consideration within methodological discussions from sociological perspectives. While I find her list to be rather novel as a practical 'starters guide' for sociologists to incorporate dimensions of projectivity (i.e., elements of future perception) into their research, it falls a bit short on methodological clarity and specificity. As such, I'm going to close this section by drawing a few general methodological connections to her 9 cognitive dimensions with some of the relational methodological principles that have been discussed up to this point. Mische's cognitive dimensions of future projection are as follows:

1-Reach: the degree of extension that an individual's perception of the future has into the short, middle, and long term.

2-Breadth: the range of possibilities considered at different points in time and actors' vision of singular or multi-pronged future possibilities and trajectories.

3-Clarity: the degree of detail and clarity with which the future is imagined. 
4-Contingency: the degree to which future trajectories are imagined as fixed and predetermined versus flexible, uncertain, and dependent on local circumstance.

5-Expandability: the degree to which future possibilities are seen as expanding or contracting, as open to change or 'locked-in'.

6-Volition: the relation of motion or influence that the actor holds in regard to the future, whether an actor has a passive stance towards the future or perception of control over it.

7-Sociality: the degree to which future projections are "peopled" with others whose actions and reactions are seen as intertwined with our own.

8-Connectivity: the imagined logic of connection between temporal elements, what are also called principles of linkage between actions and events.

9-Genre: the recognizable discursive "mode" in which future projections are elaborated, the narrative form of future projections. (Mische, 2009: 699-701)

While this list could be interpreted as a series of 'testable' cognitive dimensions for sociologists to empirically examine, it seems that each has great value at the interpretive stage of a relational research project. For instance, if we are using multiple correspondence analysis to reveal the ways in which people are positioned among social elements, we cannot simply interpret the clusters and collections of categories and properties - this is not relational - we must consider the ways in which the relational clusters might be expressed in the minds and actions of the individuals who are located within them. While Bourdieu relied heavily on survey data and data reduction techniques like MCA to reveal relational dimensions of social fields, he did not simply rely on a method that 'thinks relationally' to reveal the logic of a field, his research was relational in its interpretation as well, a point made by Breiger who argues that "despite notable counter-tendencies, [Bourdieu] seeks to push structuralist analysis as far as possible in the direction of analyzing practical actors, performance, meaningfulness as a social product, and interpenetration of cultural and symbolic action." (Breiger, 2000: 110).

Using his results to reveal the positionality of actors within economic, social, and cultural forces, his relational interpretive style paid close attention to the cognitive dimensions of sense perceptions of positionality, potentiality, and possibility. While using different language, Bourdieu was at all times engaged with the cognitive dimensions of reach, breadth, clarity, contingency, expandability, and especially volition. His recurring discussions of 'distance from necessity', 'space of freedom', 'sense for the possible', 'anticipation of probable futures', and statements like, "power to control the future requires having a grasp on the present" (Bourdieu, 2000: 221), all speak to the cognitive dimensions of how an actor might interpret the future within the context of their social circumstance. In short, Bourdieu did not limit the interpretation of his models of social reality to the numeration of a collection of forces, he extended it to sketch out the cognitive and forwardlooking contours of social position within fields.

As an application of Bourdieu's relational framework, Young (2004) provides a particularly relevant example of research that extends its interpretation into the cognitive dimensions of sense perceptions of potentiality within social spaces. Based on interviews with twenty-six young, lowincome African American men, Young presents contextual evidence about the ways in which the 
men's projection of the future was deeply interrelated with their social, economic, and cultural positioning. His investigation into his respondents' perceptions of future employment revealed a common understanding that "there's no point in seeking that which is not there in the first place" (Young, 2004: 53), views which relate to multiple levels of Mische's dimensions in terms of 'short reach', 'narrow breadth', 'practical clarity', 'fixed contingency', and 'contracting expandability'. Providing many detailed examples of the ways in which his respondents' position among social, economic, and cultural forces were related to a very narrow and limited sense of potentiality and possibility for future outcomes, Young illustrates in a very interesting way how the relational dynamics of a person's social environment translate into a relational projection of where they realistically might fit in similar social spaces in the future. Young makes the argument that the social limits play out in interesting ways as cognitive limits as well. While Young uses entirely different research techniques than Bourdieu (interview vs. survey data), he similarly interprets his results using cognitive dimensions and relationally explores the ways that social circumstance translate into future perceptions of potentiality and possibility.

Mische's cognitive dimension of sociality adhere particularly well with social network research approaches. The notion of sociality, in particular, has deep ties with social network methods, extends into the relational intersections between people in networks, and can speak to the ways social ties and limit or expand imagined futures. As discussed earlier, social network approaches have been criticized for being limited to empirical mapping of the form and structure of networks and their inhabitants and for their inability to make sense of the processes through which relations and attitudes are formed (Emirbayer \& Johnson, 2008: Hollstein, 2009). Cognitive dimensions of future orientation can be very useful for thinking relationally about how future projections are often tied to relations with other people, places, and things. Mische (2009) offers the example of researchers studying how people imagine their future interactions with romantic partners, growing children, or colleagues, and examine whether they anticipate (or fail to anticipate) tensions between intersecting social worlds (e.g. resolving work-life conflicts), or how people juggle multiple timeframes as they work to achieve a balance between their personal projects with those of the various collectivities to which they belong (699).

Speaking strictly on a methodological level, there is very little written about a relational examination of future perception and projection. This should not deter us from taking on the lofty task of figuring out ways to gather and reveal relational evidence of actors' perceptions of their future within different spatial contexts, both familiar and unfamiliar. While reading Bazeley's (2003) run-down of qualitative content analysis, which is essentially a technique for making inferences by objectively and systematically identifying characteristics of an interview or related texts, it occurred to me that it might be possible to use qualitative software programs to run searches for words, phrases, expressions, or statements that reflect dimensions of future perception and orientation (e.g. to be, later, soon, someday, possible, promise, tomorrow, foresight, outlook etc. etc.). These searches may reveal opportunities to further examine the relational context within which the future oriented statements are made. Somers (1994) also emphasizes the use of relational narrative techniques, which "demands that we discern the meaning of any single event only in temporal and spatial relationship to other events" (617). She introduces a relational concept called narrative identity which is an approach that assumes that social action can only be intelligible if we recognize that people are guided to act by the structural and cultural relationships in which they are embedded and by the stories through which they constitute their identities (Somers, 1994: 625). Her fundamentally relational point is that sociologists need to "locate actors' social narratives in 
temporal and spatial configurations of relationships and cultural practices (institutions and discourses)" (1994: 626). This point is in line with Mische (2009) and Lizardo \& Strand (2010) who argue that sociology can make its greatest contribution by focusing more on the projective qualities of temporal embedding and place more attention on the cultural, institutional, and relational grounding of future perception and orientation.

\section{Conclusion}

I came into this paper thinking I would exit the process with a deep understanding of what exactly a relational method is and what it is not. I fully expected to be making critical assertions like: MCA is the best way to think relationally, blockmodeling thinks too 'structurally' to be relational, network analyses are too focused on the 'individual' to be relational, and relational investigations of cognition are beyond the scope of sociological research entirely. What I've learned, however, is that there are not right or wrong, better or worse, or more or less relational methods out there. Relational methods are an extension of a view on the world, a means to express the dynamics of interdependence, positionality, and forces within and among people, environments, things, animals, symbols etc. A relational method is not relational by design, it becomes relational when applied within the context of relational ontological and epistemological principles. In other words, we do not choose 'relational methods', we choose methods that allow us the freedom to think relationally. While I have outlined some of the conventional methods that are used to apply relational theories, what has become clear is that future applications of relational research paradigms can benefit from taking an eclectic approach to selecting analytic techniques, drawing upon multi-contextual evidence to reveal the multi-layered social and institutional contexts of situated individuals. 


\section{References}

Abbott, A. (1990). Conceptions of time and events in social science methods. Historical Methods, 23(4), 140-51.

Bazeley, P. (2003). Computerized data analysis for mixed methods research. In Abbas Tashakkori and Charles Teddlie (eds) Handbook of Mixed Methods in Social \& Behavioural Research. London: Sage Publications. 385-423.

Bourdieu, P. (1984). Distinction: A social critique on the judgement of taste. Harvard University Press.

Bourdieu, P. (1992). Thinking about limits. Theory, Culture \& Society, 9, 37-49.

Bourdieu, P. and Wacquant, L. (1992). An Invitation to Reflexive Sociology. Chicago: The University of Chicago Press.

Bourdieu, P. (2000). Pascalian Meditations. (R. Nice, Trans.). Stanford University Press.

Breiger, R. L. (2000). A tool kit for practice theory. Poetics, 27, 91-115.

de Nooy, W. (2003). Fields and networks: Correspondence analysis and social network analysis in the framework of field theory. Poetics, 31, 305-327.

DiMaggio, P. (1986). Structural analysis of organizational fields: A blockmodel approach. Research in Organizational Behavior, 8, 335-370.

Dubois, V. and Jean-Matthieu Meon. (2013). The social conditions of cultural domination: Field, sub-field and local spaces of wind music in France. Cultural Sociology, 7(2), 127-44.

Edwards, G. (2010). Mixed-method approaches to social network analysis. National Centre for Research Methods: Review Paper. Available for download at: http://eprints.ncrm.ac.uk/842/

Emirbayer, M., and Johnson, V. (2008). Bourdieu and organizational analysis. Theory and Society, 37(1), 1-44.

Erickson, B. H. (1988). The Relational Basis of Attitudes. In Barry Wellman and S. D. Berkowitz, eds. Social Structures. New York: Cambridge University Press.

Fele, G. (2008). The phenomenal field: Ethnomethodological perspectives on collective phenomena. Human Studies, 31(3), 299-322.

Finlay, L. (2009). Debating Phenomenological Research Methods. Phenomenology \& Practice, $3,1-17$. 
Fligstein, N. \& McAdam, D. (2012). A Theory of Fields. New York: Oxford University Press.

Garfinkel, H. (1967). Studies in Ethnomethodology. Prentice-Hall: New Jersey. (pp.288)

Green, A. I. (2008). The social organization of desire: The sexual fields approach. Sociological Theory, 26(1).

Greenacre, M. (1994). Correspondence analysis and its interpretation. In M. Greenacre, \& J. Blasius (Eds.), Correspondence analysis in the social sciences: recent developments and applications. London: Academic Press.

Hollstein, B. (2009). Qualitative Approaches. In John Scott \& Peter J. Carrington, eds.: Sage Handbook of Social Network Analysis. London/New Delhi: Sage.

Ivankova, N. V., Creswell, J. W., \& Stick, S. L. (2006). Using Mixed-Methods Sequential Explanatory Design: From Theory to Practice. Field Methods, 18(1), 3-20. doi: $10.1177 / 1525822 \mathrm{X} 05282260$

Latour, B. (2005). Reassembling the Social: An Introduction to Actor-Network-Theory. New York: Oxford University Press.

Lewin, K. (1939). Field theory and experiment in social psychology: Concepts and methods. American Journal of Sociology, 44(6), 868-896.

Lizardo, O. and Michael Strand. (2010). Skills, toolkits, contexts and institutions: Clarifying the relationship between different approaches to cognition in cultural sociology. Poetics, 38, 204-227.

Logan, J. R. (2012). Making a place for space: Spatial thinking in social sciences. Annual Review of Sociology, 38, 507-24.

Martin, J. L. (2003). What is field theory? American Journal of Sociology, 109(1), 1-49.

Martin, J. L. and Matt George. (2006). Theories of sexual stratification: Toward an analytics of the sexual field and a theory of sexual capital. Sociological Theory, 24(2), 107-132.

Martin, J. L. (2011). The Explanation of Social Action. New York: Oxford University Press.

Mason, J. (2002) Qualitative Researching. London: Sage.

Mische, A. (2009). Projects and Possibilities: Researching Futures in Action. Sociological Forum, 24(3), 694-704.

Mische, A. (2011). Relational Sociology, Culture, and Agency. In John Scott \& Peter Carrington (Eds.), Sage Handbook of Social Network Analysis. Sage Press. 
Mohr, J. (2000). Introduction: Structures, institutions, and cultural analysis. Poetics, 27, 57-68.

Onwuegbuzie, A. J. and Charles Teddlie. (2003). A framework for analyzing data in mixed methods research. In Abbas Tashakkori and Charles Teddlie (eds) Handbook of Mixed Methods in Social \& Behavioural Research. London: Sage Publications. 351-85.

Rouanet, H., Ackerman, W., \& Le Roux, B. (2000). The geometric analysis of questionnaires: the lesson of Bourdieu's La Distinction. Bulletin de Methodologie Sociologique, 65, 5-18.

Savage, M. and Elizabeth B. Silva. (2013). Field analysis in cultural sociology. Cultural Sociology, 7(2), 111-26.

Silver, D. and Monica Lee. (2012). Self-relations in social relations. Sociological Theory, 30(4), 207-37.

Simmel, Georg. 1955. The Web of Group Affiliations. Glencoe: Free Press.

Small, M. (2011). How to conduct a mixed methods study: Recent trends in a rapidly growing literature. Annual Review of Sociology, 37, 57-86.

Somers, M. (1995). The narrative constitution of identity: A relational and network approach. Theory and Society, 23(5), 605-49.

Venturini, T. and Bruno Latour. (2010). The social fabric: Digital traces and quali-quantitative methods. Proceedings of Future En Seine. Available for download at: http://www.tommasoventurini.it/wp/wp-content/uploads/2011/08/TheSocialFabric.pdf

Young, A. A. (2004). The Minds of Marginalized Black Men. Princeton University Press.

Zerubavel, E. (2007). Generally speaking: The logic and mechanics of social pattern analysis. Sociological Forum, 22(2), 131-145. 